\title{
A IMPLANTAÇÃO DE EMPREENDIMENTOS HIDRELÉTRICOS NO MÉDIO ARAGUARI E A NOVA CONFIGURAÇÃO URBANA DE FERREIRA GOMES-AP, NA AMAZÔNIA BRASILEIRA
}

\author{
Eliakim dos Santos Silva ${ }^{1}$ \\ José Francisco de Carvalho Ferreira ${ }^{2}$ \\ José Alberto Tostes ${ }^{3}$
}

Resumo: A ocupação do espaço urbano por meio da organização sistemática do uso do solo confere ao planejamento urbano a responsabilidade em atribuir organização e ordenamento nas cidades. Assim, o principal objetivo deste trabalho é identificar os principais aspectos da expansão urbana da cidade de Ferreira Gomes Amapá, em decorrência de sua proximidade com 3 empreendimentos hidrelétricos (Usinas Hidrelétricas Cachoeira Caldeirão, Ferreira Gomes e Coaracy Nunes), avaliando especificamente as principais limitações deste processo sob a ótica do planejamento urbano e ordenamento territorial. Para a elaboração deste trabalho houve a busca por literatura específica nesta temática, recuperação de dados secundários em instituições públicas, além de pesquisas em campo para a validação de informações coletadas e identificação das principais zonas de expansão urbana e dos cenários decorrentes deste fenômeno.

Palavras-chave: Planejamento urbano. Expansão urbana. Configuração urbana. Empreendimentos hidreléticos. Ferreira Gomes-AP.

\section{THE IMPLEMENTATION OF HYDROELECTRIC PROJECTS IN THE MIDDLE ARAGUARI AND THE NEW URBAN CONFIGURATION OF FERREIRA GOMES- AP, IN BRAZILIAN AMAZON}

\begin{abstract}
The occupation of urban space through the systematic organization of land use holds the urban planning responsible to assign organization and planning in the cities. Therefore, the main objective of this work is to identify the main aspects of urban expansion of the city of Ferreira Gomes-Amapá, due the proximity to 3 hydroelectric projects (Hydroelectric Power Plant of Cachoeira Caldeirão, Ferreira Gomes and Coaracy Nunes), specifically assessing the main limitations of that urbanization in the urban planning and land use perspective. In order to begin this study it was done a search for specific literature on this topic, recovery of secondary data in public institutions, besides the field research to validate the information collected and identify the main areas of urban sprawl and the scenarios resulted of this phenomenon.
\end{abstract}

Keywords: Urban Planning. Urban expansion. Urban setting. Hydroelectric developments. Ferreira Gomes-AP.

\footnotetext{
1 Universidade Federal do Amapá, Departamento de Filosofia e Ciências Humanas, Macapá, Brasil, eliakimgeografia@hotmail.com, https://orcid.org/0000-0003-2409-0090

2 Universidade Federal do Amapá, Departamento de Filosofia e Ciências Humanas, Macapá, Brasil, zfcofer@gmail.com, https://orcid.org/0000-0001-8266-166X

${ }^{3}$ Universidade Federal do Amapá, Departamento de Filosofia e Ciências Humanas, Macapá, Brasil, tostes.j@hotmail.com, https://orcid.org/0000-0002-8493-4518
} 


\section{LA IMPLANTACIÓN DE EMPRENDIMIENTOS HIDROELÉCTRICOS EN EL MEDIO ARAGUARI Y LA NUEVA CONFIGURACIÓN URBANA DE FERREIRA GOMES/AP, EN LA AMAZONIA BRASILEÑA}

Resumen: La ocupación del espacio urbano por el medio de la organización sistemática del uso del suelo confiere al planeamiento urbano una responsabilidad en atribuir la organización y el ordenamiento de las comunidades. Así, el principal objetivo de este trabajo es identificar los principales aspectos de la expansión urbana de la ciudad de Ferreira Gomes - Amapá, como resultado de su proximidad con 3 proyectos hidroeléctricos (Centrales Hidroelétricos Cachoeira Caldeirão, Ferreira Gomes y Coaracy Nunes), evaluando específicamente las principales limitaciones de este proceso bajo la óptica de la planificación urbana y ordenamiento territorial. Para la elaboración de este trabajo se buscó por literatura específica en esta temática, recuperación de datos secundarios en instituciones públicas, además trabajo de campo para la validación de informaciones recolectadas e identificación de las principales zonas de expansión urbana y de los escenarios resultantes de este fenómeno.

Palabras clave: Planificación urbana. Expansión urbana. Configuración urbana. Desarrollos hidroeléctricos. Ferreira Gomes-AP.

\section{Introdução}

O expressivo aumento das cidades promoveu, após a década de 1970, mudanças expressivas nos ambientes urbanos. Após o fim da Segunda Grande Guerra Mundial, foi possível perceber mudanças na geopolítica mundial e contexto da distribuição populacional. Sabe-se que esta última, teve sua dinâmica alterada dada as profundas transformações econômicas, as quais promoveram novos significados nas relações campo-cidade em diversos países do mundo.

A implementação de estratégias desenvolvimentistas em países emergentes durante a segunda metade do século $X X$, conduziu o referido fenômeno, de forma acelerada, nas cidades receptoras de empreendimentos econômicos, marcados pelo rápido atrativo populacional provocado por fluxos de capital empregados em planos, projetos e programas voltados à reestruturação econômica de países com mercados pouco dinâmicos, o que proporcionou novas formas de configuração do espaço urbano e relações de mercado mais amplas nestas nações, consolidando uma das fases mais expressivas do sistema capitalista.

No Brasil e, em especial, no Amapá, estado da região norte, receptor do primeiro grande projeto com perspectivas desenvolvimentistas para a Amazônia (Projeto ICOMI - 1953), as cidades permaneceram submetidas, por várias décadas, à lógica tal qual supracitada, cujos cenários, outrora delineados, voltam a se repetir, com a implantação de próteses construídas para criar condições de mobilidade do 
capital internacional na exploração de commodities, como no caso da construção de usinas hidrelétricas no médio curso do rio Araguari em grande proximidade com a cidade de Ferreira Gomes.

A partir da construção destes empreendimentos, surgiram na sede urbana do município supracitado elementos diversos, promotores de transformações no uso do solo, marcadas pela ágil expansão urbana em áreas pouco consolidadas, nas quais se identificam grandes problemáticas socioambientais, que fragilizam segmentos importantes da sociedade, causando impactos na qualidade de vida e bem estar social da população local pela magnitude e frequência com que ocorrem.

Por outro lado, os pressupostos básicos do planejamento urbano ${ }^{4}$ deveriam, diante deste contexto, se apresentar como grande meio para promover o equilíbrio, a harmonização e a organização das atividades humanas sobre o espaço geográfico ocupado, para que limitações provenientes de irregularidades e falhas nas etapas de planejamento de projetos econômicos sejam minimizadas e suas potencialidades possam ser bem exploradas na busca pela sustentabilidade econômica, social e ambiental.

Em razão dos aspectos delineados, objetiva-se com este trabalho identificar os principais aspectos do padrão delineado pela recente expansão urbana encontrada na cidade de Ferreira Gomes - Amapá, avaliando, especificamente, as principais limitações deste fenômeno, sob a ótica do planejamento urbano e ordenamento territorial, e explorando as principais potencialidades que podem ser gerenciadas através de mecanismos de planejamento de áreas urbanas diante deste cenário. Avalia-se a relevância desta temática, pois sua pertinência pauta-se na severidade dos problemas encontrados e suas relações com a vida da população residente na área urbana de Ferreira Gomes.

$\mathrm{Na}$ tentativa de expor tal problemática, este trabalho divide-se em cinco eixos fundamentais. O primeiro eixo compreende as principais considerações teóricas sobre a temática deste artigo, cujo enfoque segue abordagem específica sobre planejamento urbano e ordenamento territorial e suas funções diante dos cenários de urbanização, encontrados em regiões receptoras de grandes atividades econômicas e das dinâmicas consequentes desta relação, que envolve a organização dos grupos humanos sobre o espaço geográfico.

\footnotetext{
${ }^{4}$ Entende-se como pressupostos básicos do planejamento aqueles resultantes do equilíbrio obtido nos aspectos econômicos, ambientais, sociais, institucionais, culturais e espaciais, que desembocam na busca continuada da qualidade de vida ambiental e urbana (BARCELLOS; BARCELLOS, 2004; FERRARI JUNIOR, 2004; AMADO, 2005; PELLIZZARO; HARDT, 2006; SILVA; ROMERO, 2010).
} 
Em sequência, apresentam-se nas demais seções algumas das principais características da área em estudo, bem como uma breve descrição da metodologia empregada para o alcance das metas propostas, além de discussões relacionadas aos resultados encontrados e às análises procedentes às etapas finais que culminaram com a redação deste artigo, o qual possui elementos estruturados de forma a contribuir com o gerenciamento dos problemas apontados, na busca por destacar meios eficientes de mitigar os efeitos nocivos das falhas das políticas de planejamento urbano, as quais geram impactos negativos sobre a sociedade em geral.

\section{Fundamentação Teórica}

A partir da década de 1970, a expansão urbana possibilitou a reconfiguração do espaço geográfico de muitas cidades (FERRARI-JÚNIOR, 2004). Este fenômeno tomou grandes proporções quando muitas nações passaram a adotar estratégias de desenvolvimento pensadas para suprir expectativas econômicas de grandes potências mundiais, e para tentar se desvincular de estruturas do subdesenvolvimentismo e das marcas por elas deixadas na sociedade contemporânea.

A incorporação de tais políticas desenvolvimentistas na reestruturação econômica dos países latino-americanos, principalmente durante a segunda metade do século $\mathrm{XX}$, permitiu, por exemplo, o surgimento de estratégias políticasadministrativas marcadas com intensamente pela influência da acumulação e rápida entrada de capital estrangeiro nestes países (INÁCIO, 2013).

No Brasil, este tipo de capital funcionou como elemento financiador de grande parte dos planos, projetos e programas voltados à industrialização das regiões brasileiras, como os implementados na região norte, sendo uma das regiões mais transformadas por estas frentes de desenvolvimento, após a década de 1950 (BECKER, 2001, 2004).

A criação das superintendências regionais de desenvolvimento no Brasil é um dos grandes exemplos das estratégias concebidas naquele período, uma vez que estas superintendências foram criadas institucionalmente para sustentar os planos de desenvolvimento para as regiões brasileiras, dada a necessidade de homogeneização das estruturas industriais do país.

É possível compreender, então, que, com o esforço voltado ao processo de inserção da região amazônica na economia global, o desenvolvimento regional 
ganhou grandes proporções conceituais no Brasil nesta fase de industrialização orientada pelo Estado, pois, sob a ótica do nacional desenvolvimentismo, a criação de superintendências em regiões tidas como atrasadas economicamente tenderiam a canalizar recursos para espaços com potencial para investimentos e implantação de projetos, que, por sua vez, consolidariam estes polos gerando crescimento econômico, assegurando números crescentes para a economia brasileira, cujo principal objetivo era romper com a condição periférica impregnada aos países em desenvolvimento (BECKER, 2004).

Assim, todas as regiões brasileiras passaram a ser inseridas nesta face da dinâmica econômica mundial e seus espaços passaram a ser palco de contradições do processo de globalização. Boisier (1996, apud Inácio et al., 2013, p. 11), elucida este processo quando explica que,

Concomitantemente a uma posição que envolve aspectos de uma rede de conexões, a chamada "aldeia global", também gera um efeito contraditório entre o micro e o macro. Ao mesmo tempo em que a globalização fortalece as ações da dimensão global, transforma cidades e regiões em atores de competição internacional por capital, tecnologia e mercado.

A região norte do país foi inserida neste contexto por meio da criação de grandes projetos pensados para a exploração de recursos naturais na região, que, ao serem implantados, causaram profundas modificações no modo de vida da população amazônica, no meio ambiente, na economia e em diversos outros setores da sociedade, como é evidenciado, entre outros, por Becker $(2001,2004)$.

Gonçalves (2005) explica que durante o processo de ocupação da Amazônia na formação do território brasileiro, esta passou a ser apreendida como fonte de riquezas naturais, região atrasada, vazio demográfico, periferia industrial e centro de conflitos. Esta face revela a delicada natureza de muitos significados presentes nesta região, os quais se manifestaram simultaneamente nos projetos pensados para configurarem esta porção da Amazônia brasileira como elemento de integração regional, a partir da segunda metade do século $X X$.

A Amazônia emergiu então no cenário nacional como uma região singular, não homogênea, repleta de diferentes características motivadas pelas políticas exógenas de expansão através do nacional desenvolvimentismo, que causaram profundas mudanças territoriais, demográficas, ambientais e culturais no espaço amazônico, as quais perduram até os dias atuais (BECKER, 2004).

O estado do Amapá destacou-se, neste contexto, por ter sido palco do primeiro grande projeto econômico implantado na Amazônia e pela instalação de 
diversas próteses ${ }^{5}$, construídas para criar condições de mobilidade do capital, articulação de redes e atuação do capital internacional na exploração de commodities (PORTO, 2015), impondo ao referido estado ritmos diferenciados de crescimento populacional e expansão demográfica que reconfiguraram sua formação socioespacial, ocorrendo isto mais intensamente a partir década de 1950, através da implantação de grandes objetos técnicos no território estadual.

Nesse sentido, é importante considerar, sobre a avaliação do processo histórico de ocupação do Amapá e o desenvolvimento da configuração urbana estadual, que ambos não ocorreram de forma linear, sendo caracterizados ainda por grandes flutuações no padrão demográfico, motivadas pelo contexto político e econômico regional, dado o posicionamento geográfico do território amapaense em faixa de fronteira, que a torna uma zona instável com dinâmicas intensas (INPE, 2001; SANTOS, 2012) e que tendem a apresentar, de maneira mais proeminente, o surgimento de novos assentamentos urbanos sustentados pela criação das anteriormente referidas próteses.

A configuração urbana do Amapá sob a ótica dos objetos técnicos

Observa-se que a configuração urbana estadual, sob a ótica dos objetos técnicos implementados no território amapaense, à época dos grandes projetos da Amazônia, resultou da instalação de próteses (PORTO et al., 2007), as quais seguiram indissociáveis ao processo de consolidação do capital estrangeiro no Amapá, que ocorreu por meio de estratégias desenvolvimentistas executadas sem considerar importantes especificidades regionais e locais, resultando em diversos impactos negativos para o meio ambiente e para a sociedade, tal como retratado por Becker (2004).

Serra e Fernandez (2004) explicam que estas ações, priorizadas pelo governo militar em atos objetivados à ocupação e integração da Amazônia ao restante do país, refletem, de forma clara, o planejamento autoritário e antidemocrático, cujos resultados se fazem presentes, até hoje, de forma negativa nos municípios em que tais atos foram implementados.

Esta forma de planejamento resultou no intenso crescimento demográfico em vários estados da região (principalmente os que receberam grandes projetos, como

\footnotetext{
${ }_{5}$ Para entender o significado do termo, resgata-se a definição de Porto et al. (2007), os quais explicam que as próteses podem ser entendidas como ações elaboradas por políticas externas, implantadas internamente em um local de forma a impor novos ritmos ao meio primitivo, podendo variar no modelo, mas que possuem o mesmo sentido de transformar e/ou reconfigurar um espaço que já existe.
} 
é o caso do Amapá), processo este acompanhado de fracas políticas de ordenamento territorial, gerando impactos socioambientais significativos em áreas urbanas e rurais, culminando com o fracasso da tentativa de ocupação do vale amazônico de forma eficiente e organizada (SERRA; FERNADEZ, 2004).

Nestes termos, Silva e Tostes (2008) e Silva e Tostes (2011) resgatam o sentido de que a (re)organização e a (re)configuração do espaço amapaense, por meio da modernização das redes técnicas e implantação de próteses para viabilizar a fluidez do capital internacional para os grandes projetos instalados no estado, teve a expressiva capacidade de provocar severas transformações no uso do território, nos fluxos econômicos regionais e globais e no padrão de ocupação dos espaços urbanos nas cidades receptoras de tais empreendimentos.

São citados, como grandes exemplos, os fenômenos ocorridos em Serra do Navio - AP, no âmbito do projeto ICOMI, e com Oiapoque - AP, com a construção da ponte Binacional e a interligação Norte-Sul pela BR-156, que, mesmo não superando a realidade periférica regional destes municípios e até mesmo do estado, não exclui o sentido da capacidade destes elementos em promover alterações significativas no espaço onde são implementados (SILVA; TOSTES, 2008; SILVA; TOSTES, 2011).

No âmbito deste contexto, Tostes e Ferreira (2015) explicam oportunamente que, analisar a influência destes projetos, cujos investimentos provocaram autênticos inchaços populacionais, é de fundamental importância diante da atual necessidade de avaliação da sustentabilidade dos municípios amapaenses, que permaneceram aquém do planejamento e gestão do território, marcados por políticas públicas de improviso e ações imediatistas as quais não são capazes de sustentar a ocupação ordenada do território e a regulação do uso do solo, o que pode causar impactos severos na qualidade de vida e bem estar social em diversas escalas temporais.

O surgimento do planejamento urbano na perspectiva de reconfiguração das cidades

A produção do espaço urbano é um fenômeno que tem se desenvolvido de diversas formas no mundo todo, desde a Revolução Industrial, com maior intensidade na segunda metade do século XX. Ferrari Júnior (2004) explica que esses espaços se desenvolvem, sobretudo, na lógica do capital e das necessidades humanas em um cenário de conflitos e inúmeras contradições, que podem refletir diretamente na qualidade de vida da sociedade em geral. 
De forma a evitar esta face da ocupação desordenada, o planejamento urbano regional surge como fator preponderante na construção de cidades estáveis, alocadas regionalmente em espaços conectados, de forma a privilegiar a excelência de fluxos diversos que proporcionem o aumento do bem-estar social e do desenvolvimento econômico a curto, médio e longo prazo.

Honda et al. (2015) observam que o ordenamento territorial, caracterizado como uma forma de planejamento e organização do uso de uma área com o objetivo de permitir o desenvolvimento harmônico de atividades socioeconômicas, culturais e ecológicas principalmente em regiões submetidas à veloz mobilidade de capital, deve ser uma prática notória exercida pelas instituições que possuem poder de gestão sobre o uso do solo, de forma a elevar a qualidade das condições urbanas que possuem relação com a qualidade de vida e bem estar social do cidadão.

Neste Contexto, Ugeda Júnior e Amorim (2009) e Alves (2011) explicam que a ausência destas condições básicas do modo de vida urbano pode gerar a criação de ambientes degradados, que favorecem a geração de grandes impactos na qualidade de vida da sociedade em geral. A elaboração de políticas públicas urbanas pouco eficazes, por sua vez, também proporciona a manutenção de cenários de insalubridade, que se dilatam nos espaços urbanos com intervenções pouco capazes de criar mecanismos eficientes que possam sustentar as potencialidades encontradas na organização do espaço físico e amparar ações mitigadoras sobre problemáticas ambientais, que afligem a população em geral.

Razzoline e Günther (2008) explicam, neste mesmo contexto, que a falta de implementação integrada de políticas de gestão, com ações conjuntas e ajustadas com os setores de desenvolvimento urbano, é um dos principais fatores responsáveis por falhas referentes ao enfrentamento da complexidade de elementos que evidenciam a vulnerabilidade da saúde pública e bem estar social.

Da mesma forma tal qual supracitada, nos ambientes urbanos de muitos municípios do Amapá é possível encontrar cenários que refletem falhas no planejamento urbano e ordenamento territorial, principalmente em cidades impactadas por grandes projetos econômicos.

Weiser, Uliana e Ferreira (2015) demonstram este aspecto destacando a fragilização de áreas urbanas, analisando indicadores e variáveis ambientais em três grandes cidades do estado (Macapá, Santana e Laranjal do Jari), que possuem grandes irregularidades em variáveis importantes para o bem estar social e a saúde 
ambiental, tais como o abastecimento de água para consumo e o tratamento adequado de efluentes sanitários e resíduos sólidos (Tabela 01).

Tabela 01 - Principais indicadores e variáveis ambientais das cidades de Macapá, Santana e Laranjal do Jari

\begin{tabular}{|c|c|c|c|c|c|c|c|c|c|c|}
\hline \multirow{2}{*}{ INDICADOR } & \multirow{2}{*}{ VARIÁVEL } & \multicolumn{3}{|c|}{ Macapá } & \multicolumn{3}{|c|}{ Santana } & \multicolumn{3}{|c|}{ Laranjal do Jari } \\
\hline & & 2000 & 2010 & $\Delta \%$ & 2000 & 2010 & $\Delta \%$ & 2000 & 2010 & $\Delta \%$ \\
\hline \multirow{5}{*}{ Saneamento básico } & $\begin{array}{l}\text { Percentual de domicílios atendidos direta ou indiretamente por } \\
\text { coleta de lixo domiciliar \% }\end{array}$ & 44,85 & 73,92 & 64,8 & 46,9 & 75,41 & 60,7 & 35,34 & 60,14 & 70,2 \\
\hline & $\begin{array}{l}\text { Percentual de domicílios com acesso a rede geral de esgoto ou } \\
\text { fossa séptica \% }\end{array}$ & 18,95 & 23,42 & 23,6 & 10,5 & 14,24 & 36,3 & 0,87 & 8,75 & 905,7 \\
\hline & Esgoto a ceu aberto & ---- & 55,9 & ---- & ----- & 52,7 & ---- & ----- & 70,3 & ---- \\
\hline & Lixo acumulado & ---- & 15,2 & ---- & ---- & 38,0 & ---- & ---- & 20,7 & ---- \\
\hline & Percentual de domicílios atendidos por rede pública de água \% & 53,22 & 48,36 & $-9,1$ & 54,96 & 62,1 & 13,0 & 80,21 & 77,53 & $-3,3$ \\
\hline \multirow{2}{*}{ Gestão Ambiental } & Efetividade da Estrutura de Gestão Ambiental Nro & 0 & 4 & ---- & 0 & 5 & ---- & 0 & 3 & ---- \\
\hline & Efetividade do Conselho Municipal de Meio Ambiente Nro & 0 & 4 & ---- & 0 & 3 & ----- & 0 & 3 & ---- \\
\hline \multirow{3}{*}{$\begin{array}{l}\text { Produção, valorização e } \\
\text { destino final dos Residuos } \\
\text { sólidos Urbanos }\end{array}$} & Resíduos sólidos com destino a aterro \% & 100 & 97,7 & 2,3 & 100 & 100 & 0,0 & 100 & 100 & 0,0 \\
\hline & Taxa de cobertura da coleta seletiva & 0 & 0,3 & ---- & 0 & 0 & ----- & 0 & 0 & $-\cdots$ \\
\hline & Resíduos recolhidos seletivamente por habitante & 0 & 0 & ---- & 0 & 0 & ----- & 0 & 0 & ---- \\
\hline \multirow{6}{*}{$\begin{array}{l}\text { Biodiversidade/proteção dos } \\
\text { ecossistemas }\end{array}$} & Percentual de área dedicada agricultura Orgânica & 0 & 0 & ---- & 0 & 0 & ---- & 0 & 0 & ---- \\
\hline & Áreas Protegidas & ---- & $0,05^{\star}$ & ---- & ---- & $0,07^{*}$ & ----- & ---- & $94,92^{*}$ & ---- \\
\hline & $\begin{array}{l}\text { Área desmatada do município em relação à área total } \\
\text { desmatada no estado \% }\end{array}$ & 14,83 & 13,69 & $-7,7$ & 3,59 & 2,54 & $-29,2$ & 7,54 & 6,35 & $-15,8$ \\
\hline & $\begin{array}{l}\text { Desperdício de água ( índice de perdas na distribuição de } \\
\text { água) }\end{array}$ & ---- & 77,23 & ---- & ---- & 72,5 & ---- & ---- & 85,39 & ---- \\
\hline & Áreas degradadas & ---- & $1,64^{*}$ & ---- & ---- & $0,4^{*}$ & ---- & ---- & $0,05^{*}$ & ---- \\
\hline & Consumo de água por habitante (litros/dia) & 84,4 & 67,3 & $-20,3$ & 60,3 & 71,5 & 18,6 & 62,6 & 37,4 & $-40,3$ \\
\hline Qualidade do Ar & $\begin{array}{l}\text { Emissões de monóxido de carbono emitidos por veículo para } \\
\text { cada habitante }\end{array}$ & $0,95^{\star *}$ & $1,22^{* * \star}$ & 28,4 & $0,56^{* *}$ & $0,78^{\star \star \star}$ & 39,3 & $0,21^{\star *}$ & $0,37^{* \star \star}$ & 76,2 \\
\hline
\end{tabular}

Fonte: Weiser, Uliana e Ferreira (2015). ${ }^{\star}$ Santos et al. (2014); ${ }^{* \star}$ Valores referentes a 2010; ${ }^{* *}$ Valores referentes a 2013.

Não obstante, Pantoja e Andrade (2012) exemplificam situação semelhante ao que é discutido por Weiser, Uliana e Ferreira (2015), ao versarem sobre a implantação de grandes projetos hidrelétricos, em especial os que ocorrem em Ferreira Gomes - Amapá e sua capacidade em gerar grandes transformações sociais e ambientais negativas, sobretudo, na saúde pública, percebidas já nas fases iniciais de instalação das usinas no curso médio do rio Araguari, com grande proximidade ao município mencionado.

Desta forma, tão importante quanto analisar a relevância do planejamento urbano na prevenção ou mitigação das problemáticas supracitadas como um fator primordial no acompanhamento do processo de expansão territorial e ampliação do uso do solo, também é considerado um fator essencial avaliar as causas da insuficiência dos planos urbanos-ambientais projetados para áreas sem infraestrutura básica de atendimento à população, e receptoras de próteses com potencial de grande atração de fluxos populacionais. 
Isso deve ocorrer a fim de que estas atividades sejam reformuladas sob a correta implementação de formas de planejamento ambiental, estratégico e urbanoregional, para que os planos econômicos frutifiquem e suas potencialidades se tornem duradouras, de maneira a garantir a eficiência do desenvolvimento regional na elevação dos índices ligados à melhoria da qualidade de vida da sociedade.

\section{Caracterização da área de estudo}

O município de Ferreira Gomes encontra-se localizado no estado do Amapá, distante aproximadamente 137 km da capital, Macapá. Seu núcleo urbano situa-se às margens do rio Araguari, principal rio componente da Bacia Hidrográfica do Atlântico Norte (CUNHA, 2001), que desemboca no litoral brasileiro na região que compreende as planícies costeiras do Cabo Norte (Mapa 01). Ainda que exista considerável tráfego intermunicipal e entre localidades, através do rio Araguari, 0 principal meio de acesso ao município é por via terrestre a partir da BR-156, que corta o território municipal em região de grande proximidade com a zona urbana.

Mapa 01 - Localização da área de estudo

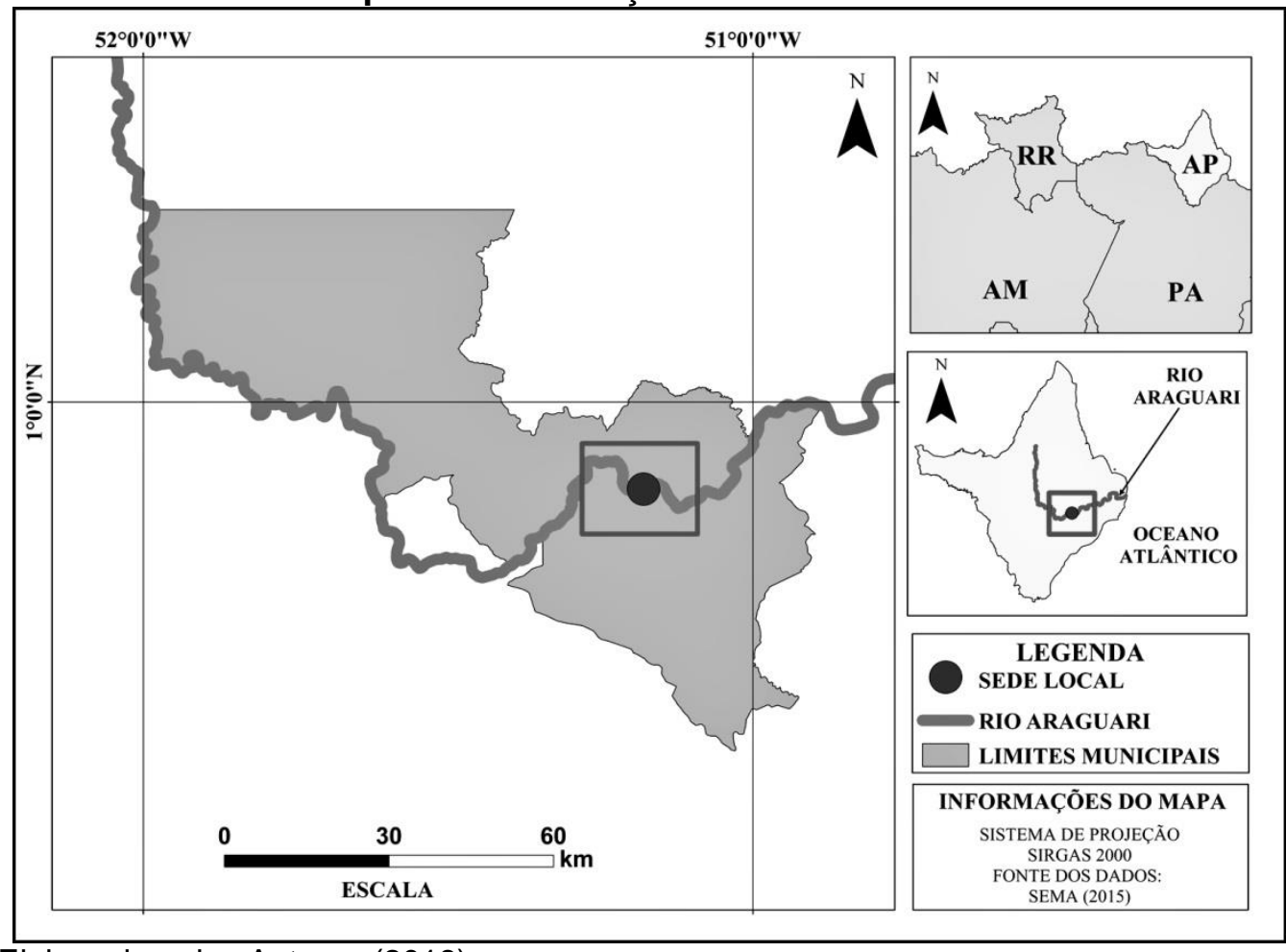

Fonte: Elaborado pelos Autores (2018).

Embora Gomes (1999) relate que a região, que compreende o território municipal da cidade estudada, esteve, por muitos anos, ligado à rota de fuga de mocambos escravos em fazendas de Macapá e Mazagão, que passavam pela região que hoje abrange Ferreira Gomes, quando de suas frequentes fugas para a área contestada por portugueses e franceses na fronteira entre Brasil e Guiana 
Francesa durante o período colonial, o Plano Diretor de Ferreira Gomes (2013) relata que, criado oficialmente no dia 17 de dezembro de 1987 pela Lei Federal no 7639/87, o município de Ferreira Gomes, até então distrito de Macapá, possui seu histórico de ocupação ligado a três momentos distintos entre os séculos XIX e XXI.

Os principais momentos, que proporcionaram novos fluxos populacionais ligados ao surgimento da cidade de Ferreira Gomes e consolidação da área urbana, são os acontecimentos atrelados à formação da colônia de barro e a colônia de prata por cabanos, por volta da década de 1830; à criação da primeira escola rural na área que viria a constituir o município de Ferreira Gomes, já na década de 1940, com a implantação da Colônia Agrícola do Matapí na região; além da construção de empreendimentos hidrelétricos no rio Araguari, nas proximidades da sede urbana do município, que, na década de 1970 e 2010, possibilitaram a inserção de novos fluxos demográficos para o referido local (PDFG, 2013).

A implementação de equipamentos públicos locais bem como sua modernização, ao longo dos anos, possibilitou ao município estudado várias transformações de ordem social, econômica e ambiental principalmente com a implantação da Usina Hidrelétrica no distrito de Paredão em Ferreira Gomes (19561976), que, na época, se configurou como o segundo maior empreendimento voltado às políticas desenvolvimentistas para o extremo norte do país entre a década de 1950 e 1970 (ELETRONORTE, 2004, 2005), responsável por algumas das mais fortes mudanças no cenário de ocupação da cidade que, à época, era predominantemente rural, com sua economia assentada no fornecimento de produtos primários, especialmente para outras localidades do estado.

$\mathrm{Na}$ atualidade, a economia de Ferreira Gomes segue pouco diversificada, com fortes bases de atividades agropecuárias tradicionais, com destaque para a pecuária e exploração de produtos agrícolas do setor primário. Há no município atividades agropastoris ligadas à extração de produtos vegetais tais como a madeira e o açaí, a produção de lavoura temporária e/ou permanente de laranja, feijão, mandioca e milho, além da criação de aves, bovinos, bubalinos, caprinos, ovinos e suínos (IBGE, 2015a).

O setor secundário do município é pouco desenvolvido, mas o setor terciário é emergente, onde se pode mencionar a existência de unidades de prestação de serviços, lojas e comercialização de mercadorias, em geral, localizados, em sua maior parte, no bairro Central, e, em menor parte, nos bairros Montanha, Portelinha e Ameixal, os quatro bairros existentes na cidade, os quais reúnem o percentual de 
população urbana na taxa dos $75 \%$ do total municipal dos aproximados sete mil habitantes contabilizados para o município (IBGE, 2015c; PDFG, 2013).

\section{Materiais e métodos}

Para a elaboração deste trabalho foram seguidos procedimentos metodológicos visando conduzir a busca e obtenção adequada de dados válidos para a referida temática. Além da procura por literatura específica sobre a problemática levantada, houve recuperação de dados secundários ajustados à área em estudo disponíveis em instituições públicas diversas. Foram utilizados mapas, gráficos e tabelas para a consolidação da pesquisa, além da realização de trabalhos de campo para auxiliar nas tarefas propostas.

As pesquisas em campo foram realizadas com o objetivo de validar informações sobre a área investigada e para a coleta de dados necessários à pesquisa. O estudo restringiu-se à área urbana, cujos limites foram definidos com base no mapa de uso do solo, o qual integra o plano diretor do município, e também com observação no nível de alteração da paisagem por meio do desenvolvimento de atividades antrópicas locais. Para possibilitar tais análises sobre essas transformações o trabalho de campo foi dividido em duas fases.

$\mathrm{Na}$ primeira fase, houve visita à área estudada para a validação de dados adquiridos em instituições públicas, assim como para a caracterização da área com o levantamento de informações primárias sobre as nuances do processo de ocupação urbana municipal. Na segunda etapa, por sua vez, ocorreram observações e registros dos principais focos de expansão urbana seguidos da avaliação das principais potencialidades e limitações deste processo identificadas no local de estudo. Em sequência às etapas de campo, os dados foram compilados, organizados e analisados para que houvesse a apreciação das informações registradas, resultando em análises referentes aos propósitos desta pesquisa.

Os produtos cartográficos foram elaborados a partir de dados recuperados da Secretaria de Estado do Meio Ambiente - SEMA, tais como os arquivos vetoriais e a fotografia aérea de alta resolução na escala de 1:25.000 do ano de 2014, proveniente do projeto "Base cartográfica digital contínua do Amapá", os quais viabilizaram a criação de mapas temáticos e formas alternativas de exploração da problemática investigada. 


\section{Resultados e discussão}

No município de Ferreira Gomes foram encontrados elementos característicos do processo de expansão urbana acelerada, provocada pelo elevado crescimento demográfico, em curto prazo, induzido pela implantação de grandes projetos locais, em alusão ao que Porto et al. (2007) e Tostes e Ferreira (2015) explicam como próteses criadas no espaço geográfico que caracterizam as flutuações demográficas e a ocupação urbana amapaense, de uma forma geral.

A implantação de empreendimentos hidrelétricos na região proporcionou a incorporação de novos cenários nos quais se evidencia o surgimento de recentes padrões de ocupação e uso do solo na sede municipal de Ferreira Gomes, devido à proximidade desta cidade com o local onde se encontram três usinas hidrelétricas (mapa 2).

Mapa 02 - Usinas hidrelétricas na bacia do rio Araguari - Amapá - Brasil

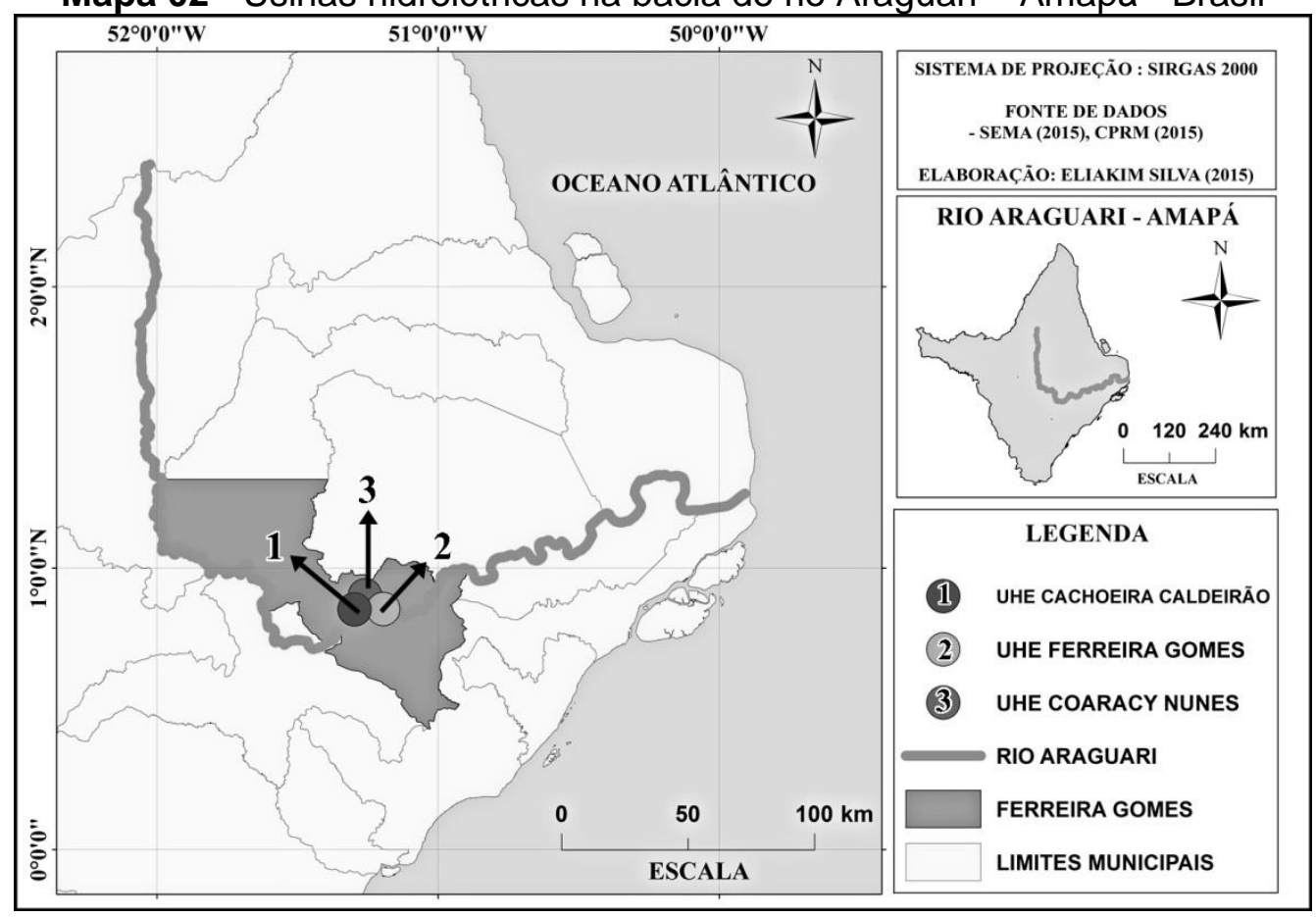

Fonte: Elaborado pelos Autores (2018).

Atualmente, na bacia hidrográfica do rio Araguari há três usinas geradoras deste tipo de energia: uma em fase de finalização, uma em fase de operacionalização e outra em pleno funcionamento, desde a segunda metade do século XX. A UHE Coaracy Nunes, em operação desde a década de 1970, quando foi inaugurada, teve sua licença de funcionamento renovada pelo governo federal em meados do ano de 2012 (ANEEL, 2012), enquanto que a UHE Ferreira Gomes a qual se encontra em fase final de operacionalização, recebeu sua licença em 2010 
(MME, 2010). A UHE Cachoeira Caldeirão, por sua vez, recebeu sua concessão em 2013 (MME, 2013), encontrando-se em estágio avançado de obras.

Observou-se, dentre os aspectos demográficos, expressivo aumento populacional no município de Ferreira Gomes, entre os anos 1991 e 2015, principalmente na quinzena que sucedeu o início do século $\mathrm{XXI}$, fatores estes relacionados diretamente com a manutenção das taxas de natalidade, inserção de novo contingente populacional vinculado à contratação mão de obra para a construção das hidrelétricas, e à própria população migrante, que encontram em cidades receptoras de grandes projetos possibilidades de melhores condições de vida.

De acordo com o Instituto Brasileiro de Geografia e Estatística (IBGE, 2015b; 2015c), a população total do município, por exemplo, aumentou em mais de $60 \%$ passando de 3.562 habitantes, em 2000, para 5.802 habitantes, em 2010. Neste sentido, ao se observar a evolução do crescimento populacional urbano, constatouse que o quantitativo de pessoas residentes na sede administrativa local, que era de 2.523 habitantes, em 2000, aumentou para 4.175 habitantes, em 2010, revelando também um aumento de mais de $60 \%$ em relação à contagem do censo anterior.

Diante do cenário, identificou-se que o instrumento de planejamento mais significativo adotado para o município é o Plano Diretor Participativo, elaborado no ano de 2013 para atender às exigências do Ministério das Cidades, em relação à obrigatoriedade deste instrumento para cidades localizadas em área de influência direta de empreendimentos de grande porte, neste caso, devido à construção das usinas hidrelétricas, anteriormente referidas.

Relativamente recente, o Plano Diretor de Ferreira Gomes possui grandes limitações referentes ao contexto de sua implantação, pois as leis urbanísticas encontradas demonstram-se incipientes, diante do cenário urbano encontrado, demonstrando a ausência de legislação específica sobre o parcelamento do uso do solo e sobre a gestão dos resíduos sólidos.

Considera-se, então, que as principais fragilidades encontradas na implementação desta forma de planejamento pensada para o município estão relacionadas à pouca eficácia na consolidação deste instrumento de planejamento frente à reconfiguração urbana da cidade, pois se avaliou que as baixas condições estruturais de gestão pública possibilitaram a gênese de um fraco empoderamento do plano diretor municipal. Cita-se, oportunamente, a falta de criação de ações complementares para que tal instrumento de planejamento pudesse tornar-se 
efetivo, tais como a elaboração de leis urbanísticas compatíveis com as novas demandas, e a captação de recursos para a estruturação de outros segmentos importantes da sociedade como saneamento e habitação.

Dividida em quatro principais bairros, pode-se afirmar que a área urbana da cidade possui duas regiões marcadas por processos diferentes, com ocorrência de impactos urbanos semelhantes, dada a relativa similaridade da ambiência local (Mapa 03). A região que compreende os bairros, Central (mais antigo) e Ameixal possui características típicas zonas de grande adensamento populacional consolidado com focos de expansão, identificadas no próprio Plano Diretor.

Mapa 03 - Zonas de adensamento e expansão urbana em Ferreira Gomes

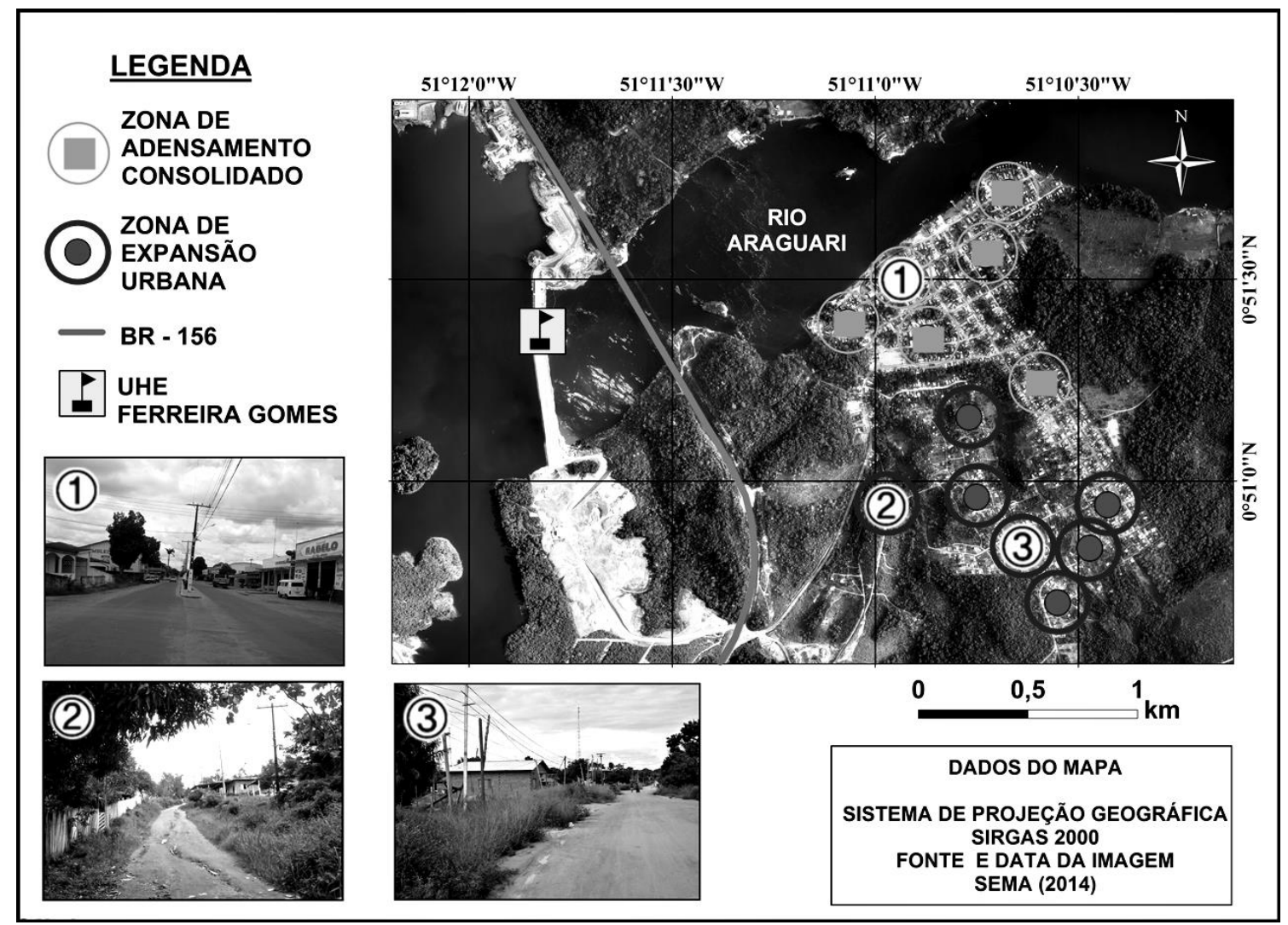

Fonte: Elaborado pelos Autores (2018).

Os bairros Montanha e Portelhinha, sendo este último o mais recente, apresentam-se com zonas de forte expansão urbana, onde também há carência de serviços públicos básicos, ocorrência de conflitos fundiários entre os que estão se assentando no local e os que se declaram donos das terras "invadidas", além de registros de impactos relacionados com a expressiva supressão de vegetação primária de terra firme, em área urbana e periurbana.

Estas atividades desenvolvidas em áreas adjacentes a regiões de expansão mais recente, ao ocorrer de maneira inadequada, pode proporcionar a disseminação de doenças como a malária e gerar cenários como o encontrado por Pantoja e 
Andrade (2012), que dão conta do aumento considerável do número de casos positivos da referida doença nas comunidades localizadas na área de influência dos três empreendimentos hidrelétricos para a bacia do rio Araguari, especificamente em Ferreira Gomes.

Dentre os principais serviços de utilidade pública básicos, o abastecimento de água com potabilidade para consumo humano e a coleta e tratamento de efluentes sanitários e resíduos sólidos foram os serviços de maior precariedade encontrados no local estudado. Considerando o Índice de Progresso Social da Amazônia brasileira (SANTOS et al., 2014), foi possível identificar baixos níveis de abastecimento de água e saneamento, que apresentaram em Ferreira Gomes um valor de apenas 35,60 pontos, muito abaixo do índice brasileiro de 74,87 pontos, mas bastante semelhante aos resultados encontrados para a Amazônia que somaram 35,35 pontos.

Encontraram-se, ainda, na área urbana da cidade impactos socioambientais relacionados à gestão de resíduos sólidos e efluentes sanitários que apresentaram respectivamente indicadores no valor de 74,14 e 7,37, classificados por Santos et al. (2014) como pontos relativamente neutros em relação a outros 30 municípios na mesma faixa de renda per capita. Alguns destes dados disponíveis para todos os municípios amapaenses são corroborados por Weiser, Uliana e Ferreira (2015) e Tostes e Ferreira (2015), os quais ponderam sobre a baixa evolução e modernização de segmentos importantes da sociedade, como o saneamento básico, a infraestrutura urbana e a educação.

Avaliou-se que a coleta e tratamento de efluentes sanitários são de extrema precariedade, pois não há qualquer tipo de sistema voltado à gestão deste tipo de resíduo que, em grande parte, são despejados nos sistemas de drenagem pluvial, igarapés urbanos e logradouros públicos, criando zonas de insalubridade que podem estar conectadas ao comprometimento da saúde pública como, por exemplo, na manutenção da taxa de mortalidade infantil no município, que era, até 2007, significativamente, superior à do Estado e do País (Tabela 02), segundo o PDFG (2013), embora tenha decrescido em anos posteriores.

Tabela 02 - Mortalidade infantil e variação percentual em Ferreira Gomes no período de 2002 a 2008, em comparação com o estado do Amapá e com o Brasil

\begin{tabular}{c|c|c|c|c|c|c|c|c}
\hline \multirow{2}{*}{ Abrangência } & \multicolumn{7}{|c}{ Taxa de Mortalidade Infantil Anual } \\
\cline { 2 - 10 } & $\mathbf{2 0 0 2}$ & $\mathbf{2 0 0 3}$ & $\mathbf{2 0 0 4}$ & $\mathbf{2 0 0 5}$ & $\mathbf{2 0 0 6}$ & $\mathbf{2 0 0 7}$ & $\mathbf{2 0 0 8}$ & Variação (\%) \\
\hline Ferreira Gomes & 21,7 & $\mathbf{3 7 , 0}$ & $\mathbf{2 9 , 4}$ & $\mathbf{3 3 , 1}$ & $\mathbf{3 0 , 8}$ & $\mathbf{3 5 , 4}$ & 7,8 & $-\mathbf{1 7 8 , 0 2}$ \\
\hline Estado do Amapá & 24,2 & 20,7 & 22,5 & 20,3 & 21,8 & 20,8 & 20,7 & $-16,90$ \\
\hline
\end{tabular}




\begin{tabular}{c|c|c|c|c|c|c|c|c}
\hline Brasil & 19,3 & 18,9 & 17,9 & 17,0 & 16,4 & 15,7 & 15,0 & $-28,66$ \\
\hline Fonte: PDFG (2013).
\end{tabular}

De acordo com o relatório de Rocha (2002), este padrão tem se propagado por todo o Amapá, onde a precariedade e baixa pontuação consequentes dos frágeis investimentos nestes segmentos são expressivas em todos os municípios amapaenses, o que promove a criação de um abismo, cada vez maior, entre as políticas urbanas que concebem o planejamento urbano regional como um sistema em rede, na qual é indispensável a análise de variáveis correlacionadas com o nível de qualidade vida da população.

Neste encalço, considerou-se que, para que as fragilidades identificadas na implementação do Plano Diretor do Município de Ferreira Gomes sejam minimizadas, é preciso que sejam criadas ações conjuntas que envolvam maior direcionamento e planejamento por parte da gestão pública municipal. Não há como pensar em melhoria na qualidade de vida da população e a eficácia na criação e consolidação de novos planos urbano-ambientais, sem antes ponderar o ordenamento territorial como uma ação de caráter democrático, perpassando necessariamente pela necessidade de gestão pública mais ampla.

Uma vez identificadas tais debilidades, o planejamento urbano tende a se apresentar como meio eficaz de transformar limitações observadas em potencialidades, desde que acompanhadas de fortalecimento institucional e da consolidação de instrumentos de planejamento elaborados com rigor que levem em consideração a ambiência local e as principais fragilidades encontradas na área urbana do município, de maneira que promovam a harmonização das atividades econômicas com os sistemas naturais e a eficácia da funcionalidade urbana como forma de elevar a qualidade de vida e bem estar social, assim como já destacado por Ferrari Júnior (2004) e Honda et al. (2015).

$\mathrm{O}$ ordenamento das atividades ocorrentes na cidade de Ferreira Gomes, o fortalecimento da legislação municipal referente ao parcelamento e uso do solo urbano, a criação e/ou modernização de infraestruturas e sistemas relacionados ao saneamento básico, são alguns pontos estratégicos que precisam ser fortalecidos e mais bem gerenciados, de forma a contribuir com o desenvolvimento municipal e elevação do padrão de vida da população residente no lugar em evidência neste estudo.

Do contrário, a inerência do poder público municipal, diante dos aspectos antes considerados, indica a repetição de cenários como os já descritos por Silva e 
Tostes (2008) e Tostes e Ferreira (2015) ao versarem sobre problemáticas semelhantes em outros municípios do Amapá, assinalando um cenário de profundas debilidades.

\section{Considerações Finais}

Foi possível avaliar que os empreendimentos hidrelétricos tiveram grande importância na atração de fluxos demográficos para o município de Ferreira Gomes, o que possibilitou o surgimento de novas formas de uso do solo e, consequentemente, a reconfiguração do espaço urbano da cidade, caracterizados principalmente pela rápida expansão urbana para uso habitacional em áreas ainda não consolidadas.

Concomitante a este fenômeno, típico de regiões que recebem grandes empreendimentos econômicos, a elaboração de fracas políticas públicas voltadas ao planejamento e ordenamento do território urbano permitiu a evolução acelerada do padrão de ocupação encontrado na área, o que gerou, por sua vez, um cenário de desordem, que reflete a falta de gestão eficaz na mitigação da problemática encontrada que é contínua e expressiva, e que pode gerar impactos negativos na qualidade de vida e bem estar social, como a disseminação de doenças pela falta de serviços de saneamento e a ocupação de áreas insalubres como encostas e zonas inundáveis.

Verifica-se, neste contexto, a gênese e evolução dos processos de crescimento demográfico e ocupação urbana acelerada de áreas que compreendem a sede administrativa do município de Ferreira Gomes que, pelas falhas na regulação deste fenômeno antrópico, dada e existência de fracas medidas de planejamento e ordenamento territorial, tendem a revelar a cenários negativos com grande comprometimento da qualidade de vida e bem estar social da população local a curto, médio e longo prazo, principalmente se a implementação de estratégias urbanísticas pouco eficazes se mantiver.

Dessa forma, é essencial pensar medidas mitigadoras para a problemática identificada a partir de uma interpretação concreta de que a eficácia na consolidação dos instrumentos de planejamento é indissociável da concepção de uma boa estrutura de gestão pública e de uma rede de ações complementares ao processo de consolidação das diretrizes estabelecidas por estes instrumentos de planejamento, indicando que o contrário pode resultar na fragilização de um mecanismo importante de ordenamento do espaço habitado. 


\section{REFERÊNCIAS}

ALVES, José C. L. Ocupação urbana e impactos ambientais: Vicente Pires - o reverso da ocupação irregular em Brasília. Dissertação (mestrado) - Programa de pós-graduação em Sociedade, Tecnologia e Meio Ambiente - Centro Universitário de Anápolis, AnápolisGo, Brasil, 2011.

AGÊNCIA NACIONAL DE ENERGIA ELÉTRICA - ANEEL. Contrato de Concessão n. 02/2012 UHE Coaracy Nunes. Brasília - DF, 2012.

AMADO, Miguel P. Planeamento Urbano Sustentável. Lisboa: Caleidoscópio, 2005.

BARCELLOS, Paulo F. P.; BARCELLOS, Luiz F. P. Planejamento urbano sob perspectiva sistêmica: considerações sobre a função social da propriedade e a preocupação ambiental. Revista da FAE, Curitiba, v. 7, n. 1, p. 129-144, jan/jun 2004.

BECKER, Bertha K. Revisão das políticas de ocupação da Amazônia: é possível identificar modelos para projetar cenários? Modelos e cenários para a Amazônia: O papel da ciência. Parcerias estratégicas, $\mathrm{n} . \stackrel{0}{12}$, p. 135-159, 2001.

BECKER, Bertha K. Amazônia: geopolítica na virada do milênio. Rio de Janeiro: Garamond, 2004.

CUNHA, S. B. Bacias Hidrográficas. In: Geomorfologia do Brasil. 2ª ed.- Rio de Janeiro: Bertrand Brasil, 2001.

CABRAL, Ligia M. M. (Org.). Eletronorte: 30 anos de pura energia brasileira. Rio de Janeiro: Centro da Memória da Eletricidade no Brasil, 2004.

CABRAL, Ligia M. M. (Org.). 30 anos de Hidrelétrica do Paredão, berço da Eletronorte. Revista Novo Norte Amapá. Ano 6. N. 13, Macapá: AP, 2005.

FERRARI JR, José C. Limites e potencialidades do planejamento urbano: Uma discussão sobre os pilares e aspectos recentes da organização espacial das cidades brasileiras.

Estudos Geográficos, Rio Claro, 2(1), p. 15-28, 2004.

GOMES, Flávio S. Fronteiras e Mocambos: o protesto negro na Guiana Brasileira. In: Flávio dos Santos Gomes (org). Nas Terras do Cabo Norte: fronteira, colonização e escravidão na Amazônia Brasileira - Séculos XVIII/XIX. Belém: Ed. Da UFPA, 1999.

GONÇALVES, Carlos W. P. Amazônia, Amazônias. São Paulo: Contexto, 2005.

HONDA, Sibila C. A. L. et al. Planejamento ambiental e ocupação do solo urbano em Presidente Prudente (SP). Revista Brasileira de Gestão Urbana, 7(1), p. 62-73, 2015.

INÁCIO, Raoni O. et al. Desenvolvimento regional sustentável: abordagens para um novo paradigma. Desenvolvimento e Gestão. Editora UNIJUÍ. Ano 11, n.ำ 24, 2013.

INSTITUTO BRASILEIRO DE GEOGRAFIA E ESTATÍSTICA - IBGE. Censo Agropecuário 2006. Rio de Janeiro, 2015a.

INSTITUTO BRASILEIRO DE GEOGRAFIA E ESTATÍSTICA - IBGE. Censo Demográfico 2000. Rio de Janeiro, $2015 b$. 
INSTITUTO BRASILEIRO DE GEOGRAFIA E ESTATÍSTICA - IBGE. Censo Demográfico 2010. Rio de Janeiro, 2015c.

INSTITUTO NACIONAL DE PESQUISAS ESPACIAIS - INPE. Análise espacial do processo de urbanização da Amazônia. Relatório Técnico. Brasília: DF, 2001.

MINISTÉRIO DE MINAS E ENERGIA - MME. Contrato de Concessão n. 02/2010 - UHE Ferreira Gomes. Brasília - DF, 2010.

MINISTÉRIO DE MINAS E ENERGIA - MME. Contrato de Concessão n.ํ 01/2013 - UHE Cachoeira Caldeirão. Brasília - DF, 2013.

PANTOJA, Giselly M. T.; ANDRADE, Rosemary F. Impactos socioambientais decorrentes dos projetos hidrelétricos na bacia do rio Araguari: do aumento populacional à disseminação da malária. Planeta Amazônia: Revista Internacional de Direito Ambiental e Políticas Públicas, n. 4, Macapá, p. 61-74, 2012

PELLIZZARO, Patrícia C.; HARDT, Letícia P. A. Efetividade do Planejamento Urbano e Regional: a Cidade Planejada e a Cidade Real. III Encontro da ANPPAS, 23 a 26 de maio de 2006, Brasília - DF. Disponível em:

http://www.anppas.org.br/encontro anual/encontro3/arquivos/TA426-06032006-

211751.PDF. Acesso em: 10 de set. 2019.

PORTO, Jadson L. R. As condições fronteiriças do Amapá: Duas abordagens para a linde sul-americana Brasil-França. Coimbra: Faculdade de Letras/Departamento de Geografia/Universidade de Coimbra, 2015.

PORTO, Jadson L. R. et al. Do território Federal a Estado: condicionantes para a execução de ajustes espaciais no Amapá. In: BRASIL, Walterlina; MIRTIL, Emanuel; MACIEL, F (Orgs.). 35 anos de colonização da Amazônia. Porto Velho: EDUFRO, p. 188-198, 2007.

PREFEITURA MUNICIPAL DE FERREIRA GOMES (PMFG). Plano Diretor Participativo Município de Ferreira Gomes. Ferreira Gomes - AP. Ferreira Gomes - Amapá, 2013.

RAZZOLINI, Maria T. P.; GÜNTHER, Wanda M. R. Impactos na Saúde das Deficiências de Acesso a Água. Saúde Soc. São Paulo, v.17, n.1, p. 21-32, 2008.

ROCHA, Sônia. Pobreza, Desenvolvimento e Política Social: o caso do Amapá. Relatório preparado para o Banco Mundial - Projeto Rain Forest, 2002.

SANTOS, Daniel et al. Índice de Progresso Social na Amazônia brasileira: IPS Amazônia 2014. Belém, PA: Imazon, 2014.

SANTOS, Emmanuel R. C. Urbanização e rede urbana na Amazônia Setentrional Amapaense/AP. Revista Formação Online, n. 19, volume 2, p. 107 -131, 2012.

SERRA, Maurício A.; FERNÁNDEZ, Ramón G. Perspectivas de desenvolvimento da Amazônia: motivos para o otimismo e pessimismo. Economia e Sociedade. Vol.13 n.ำ (23). Campinas, 2004.

SILVA, Leila S. S.; TOSTES, José A. Impactos do período pós-ICOMI, analisados pelos indicadores de qualidade de vida na cidade de Serra do Navio. Associação Nacional de Pós Graduação e Pesquisa em Ambiente e Sociedade. Brasília, 2008.

SILVA, Geovany J. A. da; ROMERO, Marta A. B.. Novos paradigmas do urbanismo sustentável no Brasil: a revisão de conceitos urbanos para o século XXI. 4 Congresso Luso-Brasileiro para o Planeamento Urbano, Regional, Integrado e Sustentável, 
Universidade do Algarve, Faro, 6 a 8 de outubro de 2010. Disponível em:

http://pluris2010.civil.uminho.pt/Actas/PDF/Paper216.pdf. Acesso em: 10 de set. 2019.

SILVA, Gutemberg V.; TOSTES, José A. Objetos técnicos que reconfiguram uma realidade periférica: notas sobre a organização do espaço amapaense vista pela ótica das redes técnicas. XIV Encontro Nacional da ANPUR, Rio de Janeiro, 2011.

TOSTES, José A.; FERREIRA, José F. C. Indicadores de sustentabilidade na aferição de impactos ambientais e urbanos nos municípios de Macapá e Santana (Amapá - Brasil). Revista Política e Desenvolvimento Regional. Rio de Janeiro, V.2, p. 91-110, 2015.

UGEDA JÚNIOR, José C.; AMORIM, Margarete C. C. T. Indicadores Ambientais e Planejamento Urbano. Caderno Prudentino de Geografia, n. 31, v. 2, p. 5-35, 2009.

WEISER, Alice A.; ULIANA, Brenda B.; FERREIRA; José F. C. Indicadores ambientais nas três maiores cidades do Amapá: Macapá, Santana e Laranjal do Jari. Revista ANAP Brasil. V.8. n.13, p. 69-83, 2015.

\section{NOTAS DE AUTOR}

\section{CONTRIBUIÇÃO DE AUTORIA}

Eliakim dos Santos Silva - Concepção. Coleta de dados, Análise de dados, Elaboração do manuscrito, Elaboração dos mapas, revisão e aprovação da versão final do trabalho.

José Francisco de Carvalho Ferreira - Concepção. Coleta de dados, Análise de dados, Elaboração do manuscrito, revisão e aprovação da versão final do trabalho.

José Alberto Tostes - Concepção. Coleta de dados, Análise de dados, Elaboração do manuscrito, revisão e aprovação da versão final do trabalho.

\section{FINANCIAMENTO}

Não se aplica.

\section{CONSENTIMENTO DE USO DE IMAGEM}

Não se aplica.

\section{APROVAÇÃO DE COMITÊ DE ÉTICA EM PESQUISA}

Não se aplica.

\section{CONFLITO DE INTERESSES}

Não se aplica.

\section{LICENÇA DE USO}

Este artigo está licenciado sob a Licença Creative Commons CC-BY. Com essa licença você pode compartilhar, adaptar, criar para qualquer fim, desde que atribua a autoria da obra.

\section{HISTÓRICO}

Recebido em: 27-09-2018

Aprovado em: 27-03-2020 